\title{
Carbon Mineralization in Ultramafic Mine Tailings: a Pathway to Negative Greenhouse Gas Emissions
}

Gregory DipPle, ${ }^{1}$ Xueya Lu, ${ }^{1}$ Sterling VANDERZee, ${ }^{1}$ Eric Wynands, ${ }^{1}$ DurJoy Baidya,${ }^{2}$ Seyed Ali GhoreishiMadiseh, ${ }^{2}$ Jamie CutTS ${ }^{1}$

${ }^{1}$ Bradshaw Research Initiative for Minerals and Mining, University of British Columbia, Vancouver, BC, Canada. gdipple@eoas.ubc.ca

${ }^{2}$ Mining Engineering, University of British Columbia, Vancouver, BC, Canada

Alkaline waste generated from mining of ultramafic rocks reacts spontaneously with atmospheric carbon dioxide $\left(\mathrm{CO}_{2}\right)$ to permanently store carbon in solid mineral form. The total capacity of these mine tailings to sequester carbon is about ten times greater than greenhouse gas emissions of associated mining and mineral processing. Waste from current mining activities globally has the capacity to sequester $100-$ $200 \mathrm{Mt}$ of $\mathrm{CO}_{2}$ per year. However passive, or unintentional, $\mathrm{CO}_{2}$ mineralization at individual mine sites is modest (1-50 kt/yr). Characterization of mine waste reactivity to $\mathrm{CO}_{2}$, expressed as labile $\mathrm{Mg}$, varies substantially between and within individual deposits. Some deposits and some types of hydrothermal alteration have the capacity to sequester $\mathrm{CO}_{2}$ far in excess of carbon emissions associated with mining through direct capture of $\mathrm{CO}_{2}$ from air. Thus, mining of this material can sequester more carbon than is emitted from mine operations. Large individual mines could sequester carbon at a net rate of a million tonnes per year - a rate commensurate with conventional carbon capture and storage facilities, but with the advantage that the $\mathrm{CO}_{2}$ is captured from air and stored in solid mineral form. This opens the possibility that mining of ultramafic rock may contribute towards achieving net-negative $\mathrm{CO}_{2}$ emissions. 